\title{
Mechanisms affecting litter sex ratio and embryo quality
}

\author{
G. Oliver ${ }^{\mathrm{A}}$ and P. Vendramini ${ }^{\mathrm{B}}$

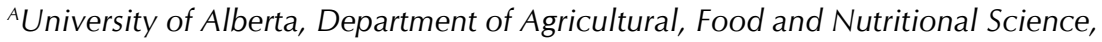 \\ 3-10V Agriculture/Forestry Centre, Edmonton, Alberta, Canada, T6C 2P5; \\ ${ }^{B}$ Departamento de Zootecnia, Universidade Federal de Viçosa, Viçosa, MG, Brasil, 36570-000
}

Sex ratios that deviate from 1:1 have been observed in response to a number of stimuli. In this review we will discuss sex ratio biasing, and the evolutionary and molecular mechanisms thought to underlie this phenomena in mammals. The role of embryo quality will be discussed in relation to sex ratio modulation and epigenetic programing of the embryo. Sex ratio skewing has been studied in many species and several factors have been proposed as influencing secondary sex ratios (body condition, maternal dominance, nutrition and developmental asynchrony). In swine, maternal nutrition has repeatedly been shown to influence offspring sex ratios, while maternal dominance and body condition exhibit less consistent evidence supporting their influence. Based on current evidence, we hypothesize that sex ratio biasing is the result of sexual dimorphisms that result in sex specific differences in embryo quality, and these differences lead to sex specific embryonic loss. The mechanisms through which sex specific loss occurs are not fully understood, however sexual dimorphisms in metabolism, gene expression and epigenetic mechanisms during early embryo development suggest that sex ratio modulation might be mediated through these mechanisms. We hypothesize that there are a number of mechanisms for skewing sex ratios in mammals, and that specific mechanisms are elicited in response to specific stimuli.

\section{Introduction}

Numerous factors influence embryo quality and offspring sex ratios, and to discuss all of these would be beyond the scope of this review: therefore, this review will focus on sex ratio modulation, and will specifically address embryo quality in relation to sex ratio biasing and programming mechanisms.

For many years investigators have been trying to answer the question of how adaptable sex ratios are within animal populations. Alteration of the sex ratio in mammals from the standard 1:1 ratio has implications for fields as diverse as evolutionary biology and livestock science, and while our understanding of the underlying theory and mechanisms of sex ratio skewing have improved, many answers remain to be found. Manipulation of sex ratio could have several economic advantages in the pig industry. Drickamer et al. $(1997,1999)$ showed that both fertility rate and teat numbers were higher in gilts born from litters with a higher proportion of females: whereas Lamberson et al. (1988) demonstrated that in litters with higher numbers of males, the females in these litters had a reduced age of puberty. These characteristics are in 
addition to the obvious advantage of being able to skew the sex for breeding purposes (more females required), or for meat production (sexual dimorphic characteristic of larger males with more muscle mass). Mammalian species usually exhibit near equality between the sexes at birth, and as sperm production arises from meiotic division of the male primordial germ cell, it would logically follow that equal numbers of $X$ and $Y$ bearing sperm would be produced and equal numbers of male and female offspring would, therefore, result. However, evolutionary biology predicts a number of conditions in which some plasticity in sex ratios might be expected (Trivers \& Willard 1973).

When discussing sex ratios and sex ratio skewing, we need to consider the sex ratio at fertilization and the sex ratio observed at birth (or even observed in utero) as potentially being different. In early studies in pigs (Parkes 1925) approximate equality between the sexes at birth was observed. However, Parkes (1925) found that the sex ratio observed in utero $(56.8 \%$ \pm 1.38 male fetuses) was significantly different to that observed at birth, and concluded that this skew towards males in utero was to ensure approximately equal numbers of males and females at birth, as fetal loss during gestation was predominantly male. This phenomenon has been extensively reported in humans (Hassold et al. 1983, Mizuno 2000), although Boklage (2005) contends that sex ratio at fertilization is equal and excessive early loss of female embryos then leaves an excess of male embryos earlier in gestation. Most mammalian species are reported to have secondary sex ratios of approximately 103-110:100 (males:females), and whilst these values are close to equal, the deviation from 1:1 is significant. Furthermore, in mammals the higher mortality seen in males in utero persists throughout life and the ratio of males to females in humans does not become equal until the fourth decade of life.

\section{Theories of sex skewing in mammalian species}

With most mammalian species showing some level of sexual dimorphism, it is easy to see that there may be a competitive advantage to being able to manipulate the numbers of males and females being born into a certain environment. Where a difference between the size of males and females exists, the extra growth potential of one sex over the other may be considered to be a competitive advantage in relation to gaining mates and food, but a disadvantage when resources are scarce in a social group. There can, therefore, be a conflict of interest between self and group in socially grouped mammals. The fact that bearing offspring is an unequal process in mammals is also of note, with the burdens and cost associated with pregnancy primarily borne by females. This means that in many mammalian species, and all domestic species, there is both sexual dimorphism and a difference in non-genetic parental investment.

\section{Trivers and Willard (Maternal metabolic investment) (1973)}

Natural selection will favour a reproductive strategy where females can bias production of their offspring from one sex to the other when their adult body condition, and by inference the expected nutritional environment of their offspring, deviates from the average. The large differences in male reproductive success mean that the mothers in a good metabolic state that have the chance to produce elite male animals will gain far more reproductive success in their offspring than if they produced females. Conversely, mothers in a relatively catabolic state, will have greater reproductive success in their offspring if they produce females. The Trivers and Willard hypothesis requires the following conditions to be met:

1. The body condition of the mother and offspring are related during the period of parental investment. 
2. Where body condition of the offspring is related to maternal body condition, this must endure to adulthood.

3. Where there is an increase in offspring body condition as a result of the period of parental investment, this results in a bigger reproductive advantage for male offspring than female offspring

\section{Local resource competition model (1978)}

Clark (1978) proposed that natural selection will favour females being able to bias the sex of their offspring when there is competition for resources within small, related, single sex groups, and that the bias will be against the sex of the group (groups are female in the pig as in most mammals). Where resources are not limited, females will bias reproduction towards producing female offspring, as these will inherit maternal social rank and territory even though they would compete for local resources. Conversely, when resources are limited, mothers will produce male offspring, as males are usually more dispersing and local resources have less influence on the future reproductive success of male offspring. Assumptions required for the local resource competition model are:

1. Social rank and territory is heritable in females.

2. The shared genetics conferred by relatedness give an evolutionary advantage to groups that have reproductive strategies that benefit the group as well as the individual.

3. Males are dispersing.

Several researchers have sought to modify these theories to better fit with observed patterns of sex skewing. Hewison \& Gaillard (1999) reviewed available data in ungulates which, when taken together, suggested that adherence to the hypothesis was associated with the degree of sexual dimorphism and levels of polygyny displayed by a species, although they concluded that these two factors together were insufficient to expect the Trivers and Willard model to apply. The Trivers-Willard model was designed to be applied to monotocous species, and this may explain why some of the results observed across ungulates are not consistent with the model. Silk (1983) extended the Local Resource Competition model to include large groups and unrelated individuals. The premise of Silk's (1983) inclusion of unrelated individuals is that while females modulate their own offspring sex ratios, they will also be able to influence the reproductive strategies of unrelated animals to further limit the numbers of females produced in the group. Such an influence may be exerted by aggressive behavior or limiting other females' access to resources. Evidence in a number of species suggests that aggression in mixed, single sex, groups occurs between unrelated individuals (Simpson et al. 1981).

Both the Trivers-Willard Model and the Local Resource Competition model predict that under certain conditions sex skewing should be observable in mammals. These hypotheses have led to the identification of a number of factors that influence sex ratio modulation in mammals.

\section{Maternal influences on sex skewing}

\section{Maternal nutrition}

Female nutrition can affect many factors that influence fertility and reproductive performance. Ovulation rate, follicular development, blastocyst development and embryo survival have all been shown to alter with changing maternal nutrition (for a review see Ashworth et al. 2009). 
Zak et al. (1997a) reported differences in weaning to estrous interval, ovulation rate and embryo survival in feed restricted first parity sows, and the effect of restriction on embryo survival was confirmed in a later study by Vinsky et al. (2006).

Maternal body condition has been used as an indicator of how well female nutritional requirements are being met, with the assumption that poor body condition reflects poor nutrition. An association between sex ratio and body condition has been observed in sheep, reindeer, red deer and roe deer (Clutton-Brock et al. 1984, Kojola \& Eloranta 1989, Sheldon \& West 2004, Blanchard et al. 2005). In domestic pigs the evidence is confounded, as rank and body condition are correlated, thus an association between maternal body condition and offspring ratio is only inferred (Meikle et al. 1993, Meikle et al. 1996). Sheldon and West (2004) identified only a weak correlation between maternal body condition and sex ratio using a meta-analysis of 37 studies in ungulate mammals, indicating that maternal body condition may not be the best measure to assess the modulation of secondary sex ratios in many mammalian species. Feed restricted mice have been shown to have female biased litters when fasted for 1 week (Meikle \& Drickamer 1986). Female dominant litters were also observed when mice were fed intermittently prior to breeding and during gestation in a follow-up study (Meikle \& Thornton 1995). Lactational feed restriction is an experimental paradigm that has been used in the pig to investigate how caloric deficits during the very intensive period of lactation affect subsequent litter characteristics (Zak et al. 1997a, Vinsky et al. 2006, Oliver et al. 2011, Patterson et al. 2011). This model has consistently shown that feed restriction during the last week of lactation affects embryo development in the next breeding cycle: However there has been a trend over time for fewer observed effects (Table 1), and in the latest iteration of this model only embryo weights and sex ratio were different between restrict-fed and control sows. The change in response to maternal catabolism observed across these models may be attributed to the effect of genetic selection during this period. The relationships between various reproductive traits are not always well elucidated, so it is highly likely that in selecting for reproductive traits such as weaning to estrous interval and litter size, other traits will have been selected for unintentionally.

Maternal diets that are deficient in certain nutrients might also be expected to lead to skewed sex ratios in the offspring. Mice that are fed low fat diets had significantly fewer males and smaller litters than mice fed control diets (Rivers \& Crawford 1974). Rosenfeld et al. (2003) used two nutritionally complete diets to investigate how the proportion of saturated fat in the diet influenced sex ratio in mice, and found that a very high saturated fat diet was associated

Table 1. Comparison of lactational restriction studies in primiparous sows. The table reports $\mathbf{P}$-values for statistically significant results, NS indicates none-significance and N/A indicates no results available.

\begin{tabular}{|c|c|c|c|}
\hline & Zak et al. $1997^{\ddagger}$ & Vinsky et al. 2006 & Oliver et al. 2011 \\
\hline Sample size (control:treatment) & 9:9 & $15: 17$ & $15: 17^{*}$ \\
\hline Weaning to oestrus interval & $<0.05$ & NS & NS \\
\hline Ovulation rate & $<0.05$ & NS & NS \\
\hline Number of live embryos & $<0.05$ & $<0.05$ & NS \\
\hline Embryonic survival (\%) & $<0.05$ & $<0.01$ & NS \\
\hline Embryonic weight & $\mathrm{N} / \mathrm{A}$ & $<0.005$ & $<0.05$ \\
\hline Litter sex ratio & $\mathrm{N} / \mathrm{A}$ & $<0.05$ & $<0.05$ \\
\hline
\end{tabular}

‡ Embryonic weight and embryo sex were not recorded by Zak et al. (1997).

* Oliver et al., (2011) selected a subset from tow forms of sows from a larger data set reported by Patterson et al., (2011). The Patterson data set consisted of control $n=49$, and restrict treatment $n=48$ ). 
with a higher proportion of males (0.67), while a diet low in saturated fat was associated with a higher proportion of females (0.39 males). Ewes fed a diet high in polyunsaturated fatty acid (PUFA) had more males than control fed ewes (69\% males) (Green et al. 2008).

\section{Maternal dominance}

When mammals live in social groups, hierarchies develop, and dominant animals in the social group have a competitive advantage over subordinates. The majority of evidence for the role of maternal rank on sex ratio skewing has been provided by studies in primates, and the evidence has been contradictory in many cases. In baboons and macaques, high-ranking mothers have more daughters than low-ranking mothers (Simpson \& Simpson 1982, Meikle et al. 1984), however spider monkeys exhibit the opposite patterns of sex skewing (Symington 1987). Brown \& Silk (2002) performed a meta-analysis using 35 data sets representing 15 primate species and concluded that maternal rank is not associated consistently with secondary sex ratios, although this was not to say that primates do not modulate their sex ratios. They found that small sample size correlated with finding statistically significant results; they also concluded that the distribution of positive and negative results was probably due to stochastic variation (Brown \& Silk 2002).

High ranking female mice produce a greater proportion of male biased litters than low ranking females, however they also appropriate more food (Meikle \& Thornton 1995). This brings into focus the issues with separating the often associated effects of dominance and nutrition. Nováková et al. (2009) looked at social and maternal history variables in laboratory colonies of spiny mice but did not find an association between maternal status and sex ratio. Given the potential benefits, it is somewhat surprising that the influence of maternal dominance in livestock species such as dairy cows and swine, has received little attention. Hohenbrink \& Meinecke-Tillmann (2012) identified a correlation between maternal dominance index and the proportion of males born to Holstein dairy cows, with higher dominance being associated with more females. Investigations on the role of maternal rank have produced mixed results in the pig. Of three studies conducted in swine, two have reported that high maternal rank was associated with more male offspring (Meikle et al. 1993, Meikle et al. 1996), and one reported that high maternal rank was not associated with offspring sex ratio (Mendl et al. 1995). Meikle et al. (1996) suggested that the lack of agreement between these studies was due to differences in the experimental methods employed. Mendl et al. (1995) created groups by mixing pigs 7 weeks into their first gestation, which Meikle (1996) argued would be after the period of any sex ratio skewing influence exerted by dominance (unless females retained dominance effects from previous social groupings). However, Mendl et al. (1995) observed and recorded data for these pigs over 4 parities, and although some confounding effects might be expected in the observations from the first parity recorded, it would be expected that subsequent sex ratio observations would be related to the dominance level as recorded within the social group that the pigs experienced across all gestations (with the caveat that females were removed from the group pen for breeding, parturition and lactation). Furthermore, the tendency for more female biased litters in high ranking mothers observed by Mendl et al. (1995) was for parity 3, when rank within the social group would have been well established. The conflicting results available to date from the small number of studies completed in the pig suggests that if there is role for maternal dominance in sex ratio skewing, it will likely be complex.

\section{Developmental asynchrony}

There have been several observations that the sexual dimorphism observed in many mammalian species can be seen in utero, and in particular that male and female embryos do not develop at the same rate. There is some evidence that differences in development rates can be related 
back to follicular development, and studies that have investigated feed restriction prior to mating have shown that reduced feed intake was associated with slowing of oocyte maturation and reduced embryo survival (Zak et al. 1997b). A follow up study extending the Zak et al. (1997b) model, found that nutritional restriction led to male biased offspring for primiparous sows, thereby demonstrating that nutritional treatments that were primarily targeted to follicular development resulted in sex ratio skewing during pregnancy (Vinsky et al. 2006). The role of follicular development in sex ratio modulation is interesting, with a growing body of evidence to support this as one mechanism underlying sex ratio biasing. However, the focus of this review is the embryo and aspects of follicular development will not be considered further (for review see Ashworth et al. 2009).

A relationship between embryo growth and sex was first illustrated by Tsunoda et al. (1985) who found that grouping in vitro cultured mouse embryos based on the time of blastocoel formation led to a segregation of males and females; fast developing embryos were skewed towards males, while slow developing embryos were skewed towards females. As in other species, there must be a level of synchronization between preparation of the uterine environment for implantation and embryonic development in the pig for pregnancy to proceed (Pope et al. 1988). The developmental asynchrony hypothesis proposed by Krackow (1995) predicts that the maternal environment might be more responsive to particular stages of embryo development: Therefore, if there are differences between males and females in early development, this might result in one sex being more successful than the other during the implantation stage, resulting in a sex ratio bias.

The developmental asynchrony hypothesis would suggest that the timing of insemination in relation to ovulation might also influence sex ratios. In mammals results have been mixed, with rodents and cattle exhibiting associations between sex ratios and insemination timing (Krackow 1997, Wehner et al. 1997), but rabbits, mice and humans showing no association (Tesh 1969, Vickers 1969, Wilcox et al. 1995). In gilts, although ovulation occurs simultaneously in the majority of follicles, a small proportion were reported to rupture over a longer time period, and these late ovulations are thought to develop into the less mature embryos when fertilized (Pope et al. 1988). Pope et al. (1986) showed that embryonic mortality at Day 30 of gestation was related to the stage of embryo development, with embryo loss being higher when there were proportionately more spherical blastocysts than ovoid, tubular and filamentous blastocysts. Although these factors would suggest that the timing of insemination in relation to ovulation could be involved in modulating sex ratios in swine, Soede et al. (2000) found no association between insemination timing and the percentage of males and have also reported little variation in the timing of ovulation among cohorts of preovulatory follicles in sows.

\section{Positioning in utero}

Many aspects of the maternal environment have been studied in relation to maternal reproductive performance, and offspring growth and reproductive performance. One interesting line of research has sought to identify how the gestational environment that a mother experienced influences her subsequent reproductive performance. Females positioned between two males in utero (2M) show offspring sex ratios biased towards males in mice, gerbils and pigs (Clark \& Galef 1995, Vandenbergh \& Huggett 1995, Drickamer et al. 1997). In mice, a bias has also been seen towards female offspring in mothers that were positioned between two females in utero $(0 \mathrm{M})$, while mothers positioned between one male and one female $(1 \mathrm{M})$ had equal numbers of male and female offspring (Vandenbergh and Huggett, 1994). It is hypothesized that testosterone, which is able to pass through the fetal membranes, is responsible for the observed skewing and the findings of Vandenbergh and Huggett (1994) would be consistent 
with a dose related response. In swine, position in utero has also been shown to affect post natal weight gain, with $2 \mathrm{M}$ boars exhibiting greater weight gains than $0 \mathrm{M}$ females, however this was only observed in nutrient restricted conditions (Rohde-Parfet et al., 1990). Drickamer et al. (1997) reported that the numbers of males within litter was related to the success ratio of insemination, and in females that came from litters that were $>67 \%$ male, conception rates at first insemination were lower.

\section{Other factors}

The evidence for the influence of maternal nutrition on modulating offspring sex ratios would suggest that other mechanisms limiting embryo access to resources could also result in skewed offspring sex ratios. In an experiment designed to investigate how the allocation of uterine length per porcine embryo influenced a number of reproductive parameters, Chen \& Dziuk (1993) found that limiting space to $<5 \mathrm{~cm} /$ corpus luteum led to a tendency for fewer males in pigs. These were similar to the results reported by Wu et al. (1988), suggesting that if spatial allocation does affect offspring sex ratio, it is not the principal modulator of offspring sex ratios in polytocous mammals. It could also indicate that where maternal nutrition has been shown to bias towards a sex, at least part of the effect is mediated through the mother rather than within the embryo itself.

Genetic studies aiming to identify factors affecting offspring sex ratios have yielded little evidence that genetic differences influence sex ratios, with associations being small when identified (see (Clutton-Brock \& Iason 1986). A recent study in red deer identified genetic differences between mothers that produced more males compared to mothers that produced more females, although this association was only found in one of the studied populations (Pérez-González et al. 2012). It is likely that offspring sex ratio is a complex multigenic trait, which would suggest low heritability. The requirement in this trait for plasticity that allows for environmental interactions, would also suggest that it would be resistant to phenotypic selection.

\section{Mechanisms}

Testosterone levels

Maternal testosterone concentration and in utero embryo exposure to testosterone are both proposed mechanisms for offspring sex ratio modulation. High maternal circulating testosterone has been associated with more male progeny in field voles (Helle et al. 2012). Grant et al. (2008) found that oocytes that developed in high testosterone follicular environments were more likely to be fertilized by Y-chromosome bearing spermatozoa and their results led them to hypothesize that testosterone might influence the composition of the zona pellucida during key points in development, favouring fertilization by X- or Y- bearing chromosomes (Grant et al. 2008). However, in a study by Bermejo-Alvarez et al. (2008) there were no differences in fertility rates between sex sorted, sex sorted and recombined, and non-sorted spermatozoa, suggesting that there was no preferential fertilization of the oocyte by spermatozoa of either sex. The role of the zona pellucida in sex ratio modulation is further brought in to question by sex ratio biases found in intracytoplasmic sperm injection (ICSI) produced embryos. Any effects of the zona pellucida is bypassed in ICSI and sex ratio biases seen at birth cannot, therefore, be the result of alterations in zona pellucida composition (Luke et al. 2009).

In humans, masculinization of mothers and high androgen concentrations at conception, have been associated with an increase in the proportion of male births (James 1990). As 
previously discussed, the maternal gestational environment experienced confers reproductive consequences when the female reaches breeding age (Vandenbergh and Huggett, 1994; Clark et al 1994; Drickamer et al. 1997).

\section{Glucose}

It has been shown that male bovine blastocysts have twice the level of glucose metabolism of female blastocysts (Tiffin et al. 1991), and in humans, male embryos showed higher uptakes of glucose and pyruvate (Ray et al. 1995). The role of glucose as an energy substrate is well defined in somatic cells; however embryos also utilize glucose for energy and it is routinely included in embryo culture medium. Bredbacka \& Bredbacka (1996) first reported an association between high levels of glucose in the culture medium and sexual dimorphism in early bovine embryos, with male embryos developing faster than females. Given the evidence for the role of developmental asynchrony in sex ratio modulation, it is likely that mechanisms shown to alter levels of sexual dimorphism in utero could also influence sex ratios. Larson et al. (2001) showed that the presence of glucose in culture medium led to a male bias in bovine embryos cultured to the expanded blastocyst stage, although interestingly they did not see any differences in growth rate between male and female embryos. Circulating levels of glucose have also been associated with offspring sex ratio biases towards increased numbers of males in several species (Machado et al. 2001, Cameron et al. 2008, Helle et al. 2012), thereby demonstrating that the influence of glucose on offspring sex ratio is not an artifact found only in vitro. Oral administration of dexamethasone resulted in lower circulating glucose levels, and the change in glucose level was predictive of offspring sex ratio (Cameron et al. 2008). In humans, patients with type 2 diabetes have been reported to have more sons than daughters, although this result was not seen for type 1 diabetics (James 2006). There is a feedback loop whereby glucose enhances luteinizing hormone release $(\mathrm{LH})$, and LH enhances glucose availability to the oocyte by up-regulating glycolysis, and this might form the mechanistic basis for glucose modulating effects on offspring sex ratios (Zuelke \& Brackett 1992, Murahashi et al. 1996).

Glucose-6-phosphate dehydrogenase (G6PD) is a housekeeping gene that encodes a key enzyme involved in the pentose phosphate pathway. Tiffin et al. (1991) reported that activity in the pentose phosphate pathway was four times higher in female bovine blastocysts compared to males. Wrenzycki et al. (2002) identified that in vitro produced bovine embryos exhibited higher G6PD expression in females than males, and this was accompanied by a significant skew towards a larger proportion of males (64:36). Similar findings have been reported in mice (Jimenez et al. 2003) and humans (Machado et al. 2001). However, as these studies were conducted in vitro, there is currently no direct evidence that these results are not related to the experimental methods used. Kimura \& Matsuyama (2012) investigated how fructose uptake affected bovine embryo development and offspring sex ratios, and they demonstrated that fructose was not associated with alterations in the development rate, or the proportion of males and females. They suggest that the differences between the effects of glucose and fructose can be explained by differences in their metabolism: Although both substrates can be utilized for glycolysis, only glucose can also be utilized by the pentose phosphate pathway (Ketterson et al. 2005). In swine, there is no direct evidence for an association between either glucose concentration or G6PD expression and offspring sex ratios: However, as with other mammalian species, G6PD can be expressed in a sexually dimorphic manner (Ronis et al. 2011). Further studies are required in the pig to discover whether glucose and the pentose phosphate pathway play the same role in sex ratio skewing described in other species. 


\section{Epigenetics}

At fertilization the principle difference between male and female zygotes is their complement of sex chromosomes. Post fertilization X-inactivation occurs in female conceptuses, and it is specifically the paternal X-chromosome that is silenced. The extra-embryonic tissues begin to develop during this time, and throughout their development these tissues retain paternal $\mathrm{X}$-chromosome inactivation. However, in the embryo there follows a period of X-reactivation, before random X-inactivation occurs. Male embryos retain an active X-chromosome throughout this period. During the period of X-reactivation in female embryos, X-linked genes are likely to show sexually dimorphic gene expression, and indeed this has been shown for a number of genes. It has been reported that the DNA methyltransferases DNMT3A and DNMT3B have sexually dimorphic gene expression in bovine blastocysts (Bourc'his \& Bestor 2006, Bermejo-Alvarez et al. 2008). These DNMTs are responsible for de novo methylation of CpG dinucleotides, and as such are important epigenetic regulators. The DNA methyltransferase 3-like protein (DNMT3L) exhibits sex-based differences in function, and although it is required for imprint establishment in female germ cells, it plays little role in imprinting in male germ cells (Bourc'his \& Bestor 2006).

In humans, prenatal exposure to famine has long-term consequences on adult health and these consequences have been shown to differ between the sexes, with male offspring having increased susceptibility to the adverse effects (for reviews see Painter et al. 2005). These later life effects are in addition to the immediate effects on growth in utero. Although birth sex ratios do not deviate from expected values for women exposed to famine during gestation (Stein et al. 2004), postnatal mortality rates are increased in their male offspring (Painter et al. 2005). Tobi et al. (2009) demonstrated differential methylation in a number of genes in response to prenatal famine exposure, and some genes exhibited sex specific alteration in their methylation patterns. Insulin-like growth factor 2 (IGF2) is a maternally imprinted gene that plays an important role in embryo development and is highly conserved across species. Hypomethylation of one IGF2 differentially methylated region (DMR) was reported in people exposed to famine (Heijmans et al. 2008). As in humans, maternal nutrition has been implicated in epigenetic changes in the offspring of mice. Kwong et al. (2006) fed mice a low protein diet during the preimplantation stage of gestation and found that mRNA expression of IGF2 and H19 were reduced compared to controls. Imprinted genes, and specifically IGF2, have also been implicated in the effects of lactational feed restriction in pigs as Oliver et al. (2011) showed a tendency for a sex-bytreatment interaction in the embryos, and sex differences in IGF2 mRNA expression have also been seen in bovine blastocysts (Gebert et al. 2009).

Our previous studies (Patterson et al. 2011) have indicated that there is a large variation in response to nutritional restriction during lactation, with some sows becoming highly catabolic and having greatly compromised embryo weights, whilst others show little catabolism and non-compromised embryo weights. Having classified sows by the level of catabolism they displayed in response to lactational feed restriction, Vendramini (2012) performed microarray analysis using the EmbryoGENE EMPV1 array (Tsoi et al. 2012) on day 9 embryos to identify 340 genes differentially expressed between High and Low catabolic sows. Ingenuity pathway analysis indicated that macromolecule metabolism, cell morphology and cellular assembly and organization were highly represented processes. Furthermore, confirmation by q RT-PCR indicated sex by sow-catabolism interactions for several genes, consistent with our previous observations for day 30 embryos (Oliver et al. 2011). We have also recently investigated global methylation in day 30 embryos from our lactational restriction model using methylseq and found DMRs associated with treatment: Moreover, the greatest methylation changes 
were observed in partially methylated sequences (G Oliver unpublished). Overall, using the cohort of samples generated from primiparous sows feed restricted during lactation, we have been able to demonstrate physiologic alterations in the embryos (Patterson et al. 2011), gene expression differences related to treatment (Oliver et al. 2011), gene expression differences related to sows lactational catabolic state ( $Z$ Ren et al. manuscript in preparation), and DMRs related to sows lactational catabolic state (G Oliver unpublished). We interpret these studies as demonstrating a link between maternal nutrition, epigenetic alterations and embryo quality, and would suggest that the epigenetic changes are responsible for the phenotypic differences in embryo quality, and as these responses are possibly sex specific, the observed sex ratio skewing may be mediated through this mechanism.

\section{Summary}

Three mechanisms could account for the modulation of sex ratios in mammalian species: 1) Sperm production could favour production of one sex. However the meiotic division that generates sperm would suggest that equal numbers would be produced and evidence supports this. 2) The oocyte might be able to recognize whether a sperm contains an $X$ or $Y$ chromosome and respond such that fertilization favours one sex. Again, there is little evidence that this happens. 3) There is sex selective loss during gestation, the mechanism(s) of which are not fully understood and may very between species. We hypothesize that sex specific loss is due to sex specific differences in embryo quality that result from sexually dimorphic responses to environmental stimuli. Sex selective loss has a large body of evidence supporting it, and as a mechanism for adaptive manipulation of sex ratios, it has a plasticity that would allow for multiple influences and responses.

There is clear evidence for maternal mechanisms mediating offspring sex ratio manipulation in swine, and sex ratio skewing has been reported in response to glucose, caloric restriction and high fat diets. It is probable that where maternal dominance has been reported to affect offspring sex ratios in pigs, this would be at least in part related to how rank affects access to nutrition. Swine models of sex ratio skewing mostly do not adhere to the Trivers-Willard hypothesis. The pig is a litter bearing species where males are dispersing and females live in groups, and it would seem that there is more evidence supporting the local resource competition model. The mechanisms that mediate sex ratio biasing in mammals are still not fully known, although the plethora of available studies would suggest that multiple mechanisms are involved (Figure 1). It might be expected that specific treatments would elicit specific mechanisms, and this might certainly be true for glucose influenced sex biasing. However, some of the longer-term consequences of offspring sex ratio skewing, such as the dip in adult reproductive performance seen in female pigs that are positioned between two males during gestation, would indicate that the embryos are being programmed in utero, and that the mechanism for these long-term outcomes is epigenetically based.

\section{Declaration of interest}

The authors have no conflicts of interest that could be perceived as prejudicing the impartiality of this review article. 


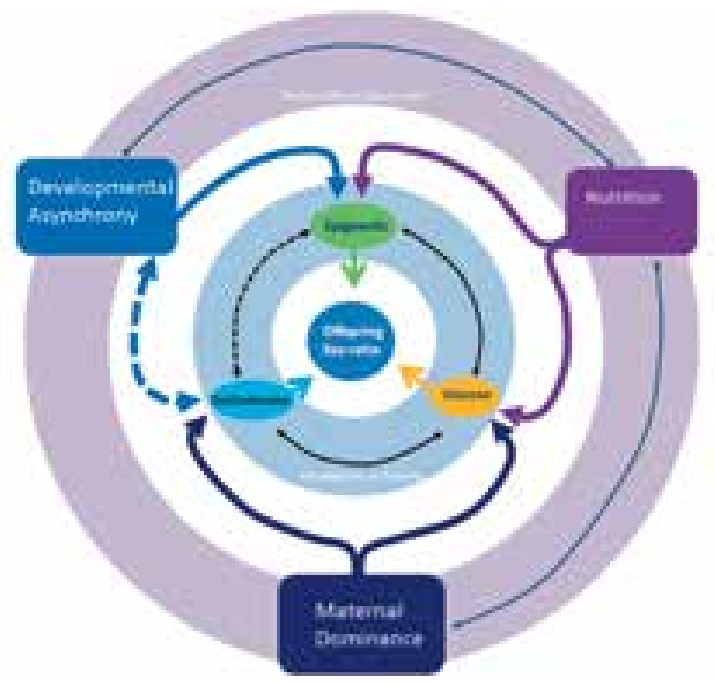

Fig. 1 Interactions between component factors influencing offspring sex ratio. Factors that have been consistently implicated in sex ratio modulation are shown in the purple outer circle, and mechanisms that may be mediating the actions of these factors are shown in the blue inner circle. The solid lines indicate direct evidence for an interaction between factors and mechanisms, and the dashed lines indicate hypothetical relationships.

\section{References}

Ashworth CJ, Toma LM \& Hunter MG 2009 Nutritional effects on oocyte and embryo development in mammals: implications for reproductive efficiency and environmental sustainability. Philosophical Transactions of the Royal Society of London Biological Sciences Series B 364 3351-3361.

Bermejo-Alvarez P, Rizos D, Rath D, Lonergan P \& Gutierrez-Adan A 2008 Can bovine in vitro-matured oocytes selectively process X-or Y-sorted sperm differentially? Biology of Reproduction 79 594-597.

Blanchard P, Festa-Bianchet M, Gaillard JM \& Jorgenson JT 2005 Maternal condition and offspring sex ratio in polygynous ungulates: a case study of bighorn sheep. Behavioral Ecology 16 274-279.

Boklage CE 2005 The epigenetic environment: secondary sex ratio depends on differential survival in embryogenesis. Human Reproduction 20 583-587.

Bourc'his D \& Bestor T 2006 Origins of extreme sexual dimorphism in genomic imprinting. Cytogenetic and genome research 113 36-40.

Bredbacka K \& Bredbacka P 1996 Glucose controls sexrelated growth rate differences of bovine embryos produced in vitro. Journal of Reproduction and Fertility 106 169-172.

Brown GR \& Silk JB 2002 Reconsidering the null hypothesis: Is maternal rank associated with birth sex ratios in primate groups? Proceedings of the National Academy of Scieinces U S A 99 11252-11255.

Cameron EZ, Lemons PR, Bateman PW \& Bennett NC 2008 Experimental alteration of litter sex ratios in a mammal. Proceedings of Biological Sciences 275 323-327.

Chen ZY \& Dziuk PJ 1993 Influence of initial length of uterus per embryo and gestation stage on prenatal survival, development, and sex ratio in the pig. Journal of Animimal Science 71 1895-1901.
Clark AB 1978 Sex ratio and local resource competition in a prosimian primate. Science (New York, NY) 201163.

Clark MM \& Galef BG, Jr. 1995 A gerbil dam's fetal intrauterine position affects the sex ratios of litters she gestates. Physiology and Behavior 57 297-299.

Clutton-Brock T, Albon S \& Guinness F 1984 Maternal dominance, breeding success and birth sex ratios in red deer. Nature 308 358-360.

Clutton-Brock TH \& Iason GR 1986 Sex ratio variation in mammals. Quarterly Review of Biology 61 339-374.

Drickamer L, Rosenthal T \& Arthur R 1999 Factors affecting the number of teats in pigs. Journal of Reproduction and Fertility 115 97-100.

Drickamer LC, Arthur RD \& Rosenthal TL 1997 Conception failure in swine: importance of the sex ratio of a female's birth litter and tests of other factors. Journal of Animal Science 75 2192-2196.

Gebert C, Wrenzycki C, Herrmann D, Gröger D, Thiel J, Reinhardt R, Lehrach H, Hajkova P, Lucas-Hahn A \& Carnwath JW 2009 DNA methylation in the < i $>$ IGF $2</$ i $>$ intragenic DMR is re-established in a sex-specific manner in bovine blastocysts after somatic cloning. Genomics 94 63-69.

Grant V, Irwin R, Standley N, Shelling A \& Chamley L 2008 Sex of bovine embryos may be related to mothers' preovulatory follicular testosterone. Biology of Reproduction $\mathbf{7 8}$ 812-815.

Green MP, Spate LD, Parks TE, Kimura K, Murphy CN, Williams JE, Kerley MS, Green JA, Keisler DH \& Roberts RM 2008 Nutritional skewing of conceptus sex in sheep: effects of a maternal diet enriched in rumen-protected polyunsaturated fatty acids (PUFA). Reproductive Biology and Endocrinology 6 21-32.

Hassold T, Quillen S \& Yamane J 1983 Sex ratio in spontaneous abortions. Annals of human genetics 47 39-47. 
Heijmans BT, Tobi EW, Stein AD, Putter H, Blauw GJ, Susser ES, Slagboom PE \& Lumey L 2008 Persistent epigenetic differences associated with prenatal exposure to famine in humans. Proceedings of the National Academy of Sciences 105 17046-17049.

Helle S, Laaksonen T \& Huitu O 2012 Sex-specific offspring growth according to maternal testosterone, corticosterone, and glucose levels. Behavioral Ecology 24 205-212.

Hewison AJ \& Gaillard JM 1999 Successful sons or advantaged daughters? The Trivers-Willard model and sex-biased maternal investment in ungulates. Trends Ecology and Evolution 14 229-234.

Hohenbrink S \& Meinecke-Tillmann S 2012 Influence of social dominance on the secondary sex ratio and factors affecting hierarchy in Holstein dairy cows. Journal of Dairy Science 95 5694-5701.

James WH 1990 The hypothesized hormonal control of human sex ratio at birth-an update. Journal of Theoretical Biology 143 555-564.

James WH 2006 The sex ratios of offspring of diabetic parents. Diabetic Medicine 23 1043-1044.

Jimenez A, Madrid-Bury N, Fernandez R, Perez-Garnelo S, Moreira P, Pintado B, de la Fuente J \& GutierrezAdan A 2003 Hyperglycemia-induced apoptosis affects sex ratio of bovine and murine preimplantation embryos. Molecular Reproduction and Development 65 180-187.

Ketterson ED, Nolan V, Jr. \& Sandell M 2005 Testosterone in females: mediator of adaptive traits, constraint on sexual dimorphism, or both? American Naturalist 166 Suppl 4 S85-98.

Kimura K \& Matsuyama S 2012 Sexual Dimorphism during Early Embryonic Development in Mammals. Journal of Mammalian Ova Research 29 103-112.

Kojola I \& Eloranta E 1989 Influences of maternal body weight, age, and parity on sex ratio in semidomesticated reindeer (Rangifer t. tarandus). Evolution 43 1331-1336.

Krackow S 1995 The developmental asynchrony hypothesis for sex ratio manipulation. Journal of Theoretical Biology 176 273-280.

Krackow S 1997 Effects of mating dynamics and crowding on sex ratio variance in mice. Journal of Reproduction and Fertility 110 87-90.

Kwong WY, Miller DJ, Ursell E, Wild AE, Wilkins AP, Osmond C, Anthony FW \& Fleming TP 2006 Imprinted gene expression in the rat embryo-fetal axis is altered in response to periconceptional maternal low protein diet. Reproduction 132 265-277.

Lamberson WR, Blair RM, Rohde Parfet KA, Day BN \& Johnson RK 1988 Effect of sex ratio of the birth litter on subsequent reproductive performance of gilts. Journal of Animal Science 66 595-598.

Larson MA, Kimura K, Kubisch HM \& Roberts RM 2001 Sexual dimorphism among bovine embryos in their ability to make the transition to expanded blastocyst and in the expression of the signaling molecule IFNtau. Proceedings of the National Academy of Sciences U S A 98 9677-9682.
Luke B, Brown MB, Grainger DA, Baker VL, Ginsburg E, Stern JE \& Society for Assisted Reproductive Technology Writing G 2009 The sex ratio of singleton offspring in assisted-conception pregnancies. Fertility and Sterility 92 1579-1585.

Machado AF, Zimmerman EF, Hovland Jr DN, Weiss R \& Collins MD 2001 Diabetic embryopathy in C57BL/6] mice altered fetal sex ratio and impact of the splotch allele. Diabetes 50 1193-1199.

Meikle D \& Drickamer LC 1986 Food availability and secondary sex ratio variation in wild and laboratory house mice (Mus musculus). Journal of Reproduction and Fertility 78 587-591.

Meikle D \& Thornton M 1995 Premating and gestational effects of maternal nutrition on secondary sex ratio in house mice. Journal of Reproduction and Fertility 105 193-196.

Meikle D, Tilford B \& Vessey S 1984 Dominance rank, secondary sex ratio, and reproduction of offspring in polygynous primates. American Naturalist 123 173-188.

Meikle DB, Drickamer LC, Vessey SH, Arthur RD \& Rosenthal TL 1996 Dominance rank and parental investment in swine (Sus scrofa domesticus). Ethology 102 969-978.

Meikle DB, Drickamer LC, Vessey SH, Rosenthal TL \& Fitzgerald KS 1993 Maternal dominance rank and secondary sex ratio in domestic swine. Animal Behaviour 46 79-85.

Mendl M, Zanella AJ, Broom DM \& Whittemore CT 1995 Maternal social status and birth sex ratio in domestic pigs: an analysis of mechanisms. Animal Behaviour 50 1361-1370.

Mizuno R 2000 The male/female ratio of fetal deaths and births in Japan. The Lancet 356 738-739.

Murahashi K, Bucholtz D, Nagatani S, Tsukahara S, Tsukamura H, Foster D \& Maeda K 1996 Suppression of luteinizing hormone pulses by restriction of glucose availability is mediated by sensors in the brain stem. Endocrinology 137 1171-1176.

Nováková $M$, Vašáková B, Kutalová $H$, Galeštoková K, Prušová K, Šmilauer P, Šumbera R \& Frynta D 2009 Secondary sex ratios do not support maternal manipulation: extensive data from laboratory colonies of spiny mice (Muridae: Acomys). Behavioral Ecology and Sociobiology 64 371-379.

Oliver G, Novak S, Patterson J, Pasternak J, Paradis F, Norrby M, Oxtoby K, Dyck M, Dixon W \& Foxcroft G 2011 Restricted feed intake in lactating primiparous sows. II. Effects on subsequent litter sex ratio and embryonic gene expression. Reproduction, Fertility and Development 23 899-911.

Painter RC, Roseboom TJ \& Bleker OP 2005 Prenatal exposure to the Dutch famine and disease in later life: an overview. Reproductive toxicology (Elmsford, NY) 20345.

Parkes A 1925 Studies on the sex-ratio and related phenomena. Annals of Applied Biology 10 287-292.

Patterson J, Smit M, Novak S, Wellen A \& Foxcroft G 2011 Restricted feed intake in lactating primiparous 
sows. I. Effects on sow metabolic state and subsequent reproductive performance. Reproduction, Fertility and Development 23 889-898.

Pérez-González J, Carranza J \& Mateos C 2012 Mothers that produce sons and daughters are genetically different in red deer. Mammalian Biology - Zeitschrift für Säugetierkunde 77 147-150.

Pope W, Lawyer M, Nara B \& First N 1986 Effect of asynchronous superinduction on embryo survival and range of blastocyst development in swine. Biology of Reproduction 35 133-137.

Pope W, Wilde M \& Xie S 1988 Effect of electrocautery of nonovulated day 1 follicles on subsequent morphological variation among day 11 porcine embryos. Biology of Reproduction 39 882-887.

Ray P, Conaghan J, Winston R \& Handyside A 1995 Increased number of cells and metabolic activity in male human preimplantation embryos following in vitro fertilization. Journal of Reproduction and Fertility 104 165-171.

Rivers J \& Crawford M 1974 Maternal nutrition and the sex ratio at birth. Nature 252 297-298.

Rohde-Parfet KA, Lamberson WR, Rieke AR, Cantley TC, Ganjam VK, vom Saal FS, Day BN 1990 Intrauterine position effects in male and female swine: subsequent survivability, growth rate, morphology and semen characteristics. Journal of Animal Science 68 179-185.

Ronis MJJ, Chen Y, Shankar K, Gomez-Acevedo H, Cleves MA, Badeaux J, Blackburn ML \& Badger TM 2011 Formula feeding alters hepatic gene expression signature, iron and cholesterol homeostasis in the neonatal pig. Physiological genomics 43 1281-1293.

Rosenfeld CS, Grimm KM, Livingston KA, Brokman AM, Lamberson WE \& Roberts RM 2003 Striking variation in the sex ratio of pups born to mice according to whether maternal diet is high in fat or carbohydrate. Proceedings of the National Academy of Sciences $U$ $S$ A 100 4628-4632.

Sheldon BC \& West SA 2004 Maternal dominance, maternal condition, and offspring sex ratio in ungulate mammals. American Naturalist 163 40-54.

Silk JB 1983 Local resource competition and facultative adjustment of sex ratios in relation to competitive abilities. American Naturalist 121 56-66.

Simpson M \& Simpson A 1982 Birth sex ratios and social rank in rhesus monkey mothers. Nature 300 440-441.

Simpson M, Simpson A, Hooley J \& Zunz M 1981 Infantrelated influences on birth intervals in rhesus monkeys. Nature 290 49-51.

Soede N, Nissen A \& Kemp B 2000 Timing of insemination relative to ovulation in pigs: effects on sex ratio of offspring. Theriogenology 53 1003-1011.

Stein AD, Zybert PA \& Lumey L 2004 Acute undernutrition is not associated with excess of females at birth in humans: the Dutch Hunger Winter. Proceedings of the Royal Society of London. Series B: Biological Sciences 271 S138-S141.

Symington MMF 1987 Sex ratio and maternal rank in wild spider monkeys: when daughters disperse. Behavioral Ecology and Sociobiology 20 421-425.
Tesh J 1969 Effects of the ageing of rabbit spermatozoa in utero on fertilization and prenatal development. Journal of Reproduction and Fertility 20 299-306.

Tiffin G, Rieger D, Betteridge K, Yadav B \& King W 1991 Glucose and glutamine metabolism in preattachment cattle embryos in relation to sex and stage of development. Journal of Reproduction and Fertility 93 125-132.

Tobi EW, Lumey L, Talens RP, Kremer D, Putter H, Stein AD, Slagboom PE \& Heijmans BT 2009 DNA methylation differences after exposure to prenatal famine are common and timing-and sex-specific. Human molecular genetics 18 4046-4053.

Trivers RL \& Willard DE 1973 Natural selection of parental ability to vary the sex ratio of offspring. Science 179 90-92.

Tsoi S, Zhou C, Grant JR, Pasternak JA, Dobrinsky J, Rigault P, Nieminen J, Sirard MA, Robert C, Foxcroft GR \& Dyck MK 2012 Development of a porcine (Sus scofa) embryo-specific microarray: array annotation and validation. BMC Genomics 13370 -385.

Tsunoda Y, Tokunaga T \& Sugie T 1985 Altered sex ratio of live young after transfer of fast- and slow- developing mouse embryos. Gamete research 12 301-304.

Vandenbergh JG \& Huggett CL 1995 The anogenital distance index, a predictor of the intrauterine position effects on reproduction in female house mice. Laboratory animal science 45 567- 573.

Vendramini P 2012 Gene expression in sows with high and low ovulation rate, high and low birth weight litters and the effect of sow catabolic status on embryonic gene expression. PhD thesis. Universidade Federal de Viçosa, Brasil.

Vickers AD 1969 Delayed fertilization and the prenatal sex-ratio of the mouse. Journal of Reproduction and Fertility 20 63-68.

Vinsky M, Novak S, Dixon W, Dyck M \& Foxcroft G 2006 Nutritional restriction in lactating primiparous sows selectively affects female embryo survival and overall litter development. Reproduction, Fertility and Development 18 347-355.

Wehner G, Wood C, Tague A, Barker D \& Hubert H 1997 Efficiency of the OVATEC unit for estrus detection and calf sex control in beef cows. Animal Reproduction Science 46 27-34.

Wilcox AJ, Weinberg CR \& Baird DD 1995 Timing of sexual intercourse in relation to ovulation-effects on the probability of conception, survival of the pregnancy, and sex of the baby. New England Journal of Medicine 333 1517-1521.

Wrenzycki C, Lucas-Hahn A, Herrmann D, Lemme E, Korsawe K \& Niemann H 2002 In vitro production and nuclear transfer affect dosage compensation of the X-linked gene transcripts G6PD, PGK, and Xist in preimplantation bovine embryos. Biology of Reproduction 66 127-134.

Wu M, Hentzel M \& Dziuk P 1988 Effect of stage of gestation, litter size and uterine space on the incidence of mummified fetuses in pigs. Journal of Animal Science $\mathbf{6 6} 3202$. 
Zak L, Cosgrove J, Aherne F \& Foxcroft G 1997a Pattern of feed intake and associated metabolic and endocrine changes differentially affect postweaning fertility in primiparous lactating sows. Journal of Animal Science 75 208-216.

Zak L, Xu X, Hardin R \& Foxcroft G 1997b Impact of different patterns of feed intake during lactation in the primiparous sow on follicular development and oocyte maturation. Journal of Reproduction and Fertility 110 99-106.

Zuelke K \& Brackett B 1992 Effects of luteinizing hormone on glucose metabolism in cumulus-enclosed bovine oocytes matured in vitro. Endocrinology 131 26902696. 